\title{
Initiative Monitoring Strategy and Tactics in Medical Professional Discussions
}

\author{
Nikolay Shamne ${ }^{1^{*}}$, Maria Nevzorova \\ ${ }^{1}$ German and Roman philology department, Volgograd State University, Volgograd, Russia \\ ${ }^{2}$ Department of Foreign Languages with a Latin Course, Volgograd State Medical University, Volgograd, Russia
}

\begin{abstract}
The paper focuses on the initiative monitoring strategy in medical professional discussions. The initiative monitoring strategy is realized by means of passing a communicative initiative tactic, imposing a communicative initiative tactic, taking a communicative initiative tactic, keeping a communicative initiative tactic, and closing an interaction tactic. The research is based on English texts of medical professional discussions, freely available on the Internet. The discourse analysis of medical professional discussion texts is used as the research method to uncover the mechanisms behind meeting talk. The aim of the article is to expose the devices for realization of the above-mentioned tactics. The leading role in discussion of development belongs to a moderator being responsible for passing an initiative and closing an interaction. Invited experts can also participate in a turn-taking process by taking and keeping an initiative.
\end{abstract}

\section{Introduction}

The dialogue is always an active interaction of communicative partners; it develops due to exchange of communicative roles (taking the role of a speaker and a listener). During the communicative move the speaker being legitimized to speak is contributing to the dialogue development while his communicative partners taking a break are also participating in interaction [1]. The proper conversation development is supposed to be a regular exchange of utterances between communicative partners.

Sometimes usual turn-taking organization in conversation may be disturbed by the participants. Initiative may be captured or imposed to a communicative partner, so the speaker's initiative and the listener's initiative should be differentiated in a turntaking process. On the one hand, the role of speaker may be passed to a listener in three ways: 1) the next speaker is appointed by means of vocatives; 2) the next speaker is imposed to talk by means of an initiative move (the first speaker asks a question so the next speaker has to answer); 3) the next speaker may empower himself to talk, if it does not occur then the previous speaker proceeds the conversation. On the other hand, the turntaking process depends on the type of listener's initiative taking. The exchange of communicative roles in a dialogue may be performed: 1) according to 'smooth' scenario [2]; 2) as a result of interjection of a partner; 3 ) after a pause $[3,4]$.

Informal and formal types of discourse may differ in turn-taking rules. A participant can easily understand in what kind of turn-taking organization he is involved [5]. Institutional interaction has a fixed turn-taking organization and participants' contribution to a conversation is usually predictable [6]. This paper explores turn-taking organization in a medical professional discussion, which is considered as a formal talk.

\section{Turn-taking organization in medical professional discussions}

Turn-taking expresses the dynamic discourse development and is verbalized in metacommunicative utterances in official conversations and discussions. Scientific professional discussion as a communicative event of dialogic interaction has a linear structure composed by a sequential exchange of communicative moves [7]. This sequence organization is considered as a communicative strategy. Communicative strategy is a part of participants' communicative behavior in which sequences of verbal and non-verbal means are used to achieve a communicative goal [8]. According to Issers' assumption that the communicative initiative redistribution is always associated with disturbances in natural conduct of interaction, participants take steps consciously to affect the communicative development [9]. Such strategic impact on the conversation is realized by means of initiative monitoring strategy that includes different tactics. A detailed classification of these tactics is based on the following parameters: 1) speaker's passing or keeping his initiative; 2) voluntary / compulsory turn-taking; 3 ) whether the tactic is aimed at turn-taking, keeping the role of a speaker or closing the conversation. The first two types of the tactics include communicative moves implemented by both speaker's

* Corresponding author: nevzorovamaria@gmail.com 
and listener's efforts. In this article we place emphasis on the initiative monitoring strategy resulting in the use of the following tactics: passing a communicative initiative, imposing a communicative initiative, taking a communicative initiative, capturing a communicative initiative, and closing an interaction. The aim of the article is to consider the realization of the mentioned tactics in medical professional discussions.

\section{Initiative monitoring strategy and tactics}

Medical professional discussions are characterized by a fixed question - answer order, in which roles are clearly defined as a moderator and invited experts. In medical professional discussions a disposal of a communicative initiative belongs to a moderator. This role entitles a participant to pass a communicative initiative, to govern a thematic organization of a discussion. Turn-taking in conversations is implemented by means of speaker's efforts or listener's efforts. Its usual realization is considered as a minimal unit of communicative exchange that is initial and responsive moves (a question - an answer to the question; a stimulus - a response to the stimulus).

\subsection{Passing a communicative initiative tactic}

In medical professional discussions passing a communicative initiative occurs due to the speaker's intention to give an opportunity of expressing ideas to his partners. This tactic is verbalized by means of a direct vocative, calling the next speaker.

- Dr. Fleg, do you foresee that there are going to be any changes in the rates of cardiovascular disease...?

- Doctor W, is there anything on the X-ray of 1956 that ought to be of interest?

- Dr. Wolf, regarding the informed decision-making process, ACS has consistently supported this concept. Can you define informed decision making and explain its importance? [Medical Roundtable].

The initial position of the vocative in the utterances draws expert's attention to the question and marks a communicative situation as official one, assigning a formal tone to the discussion.

The material analysis has shown that vocatives can be differentiated into two groups. The first group includes official vocatives while the second group comprises those indicating minimization of the distance between the participants using only first name to address a communicative partner. Official vocative is a prototypical form in medical professional discussions that is usually composed of special vocative Dr. (Doctor) and last name to mark a high status of an addressee (Dr. D., let me start with you. / Doctor B., let me ask you the next question... ).

Although medical professional discussion is primarily formal communication with highly ritual and conventionally stable speech patterns [10], so all participants act in accordance with their role and tend to adhere to social distance. In some cases if communicative partners are equal in the communicative status, it is possible to use only first name instead of special vocative to make a situation less formal (Let me start with a question for Dr. B. / Brad, can you give us your analysis of this trial? / I'll start with you, Dave. / John, just to follow up on that: If you were to set up a CPX laboratory not for a clinical trial, but for clinical care, to what kinds of considerations would you pay a lot of attention?).

Another means of passing a communicative initiative is using utterances calling a name of the next speaker (Let me direct this question to Dr. U. ... / We'll start with Dr. R. ... / I want to call on Dr. S. to review the $x$-ray and then we will discuss this problem. / I think Dr. Z. will show us a good deal of myocardial disease...) or pointing at him by employing personal pronouns (I'm going to ask you all... / Let me ask a question to both of you...).

Passing a communicative initiative is implemented by means of initiative questions (What exact calcium bath is being used? / What are your thoughts on that analysis?) in combination with vocative. Here are some examples. Example 1: situational context: A. - a moderator, B. - an invited expert:

A: Pieter, that's a perfect segue to you because I think HDF is quite a bit common in Europe. ... What do you think of that from a European perspective?

$B$ : Of course, the European perspective is that HDF is much more common than in the US with a penetrance of about 40\% if I'm correct ... [Medical Roundtable].

Example 2: situational context: A. - a moderator, B. - an invited expert:

A: Alan, you were the lead author in the American Society of Hypertension (ASH) Position Paper on combination therapy in hypertension. Would you comment on the evidence base for both Shawna's recommendation of treating $\mathrm{BPs}$ of $150 / 95 \mathrm{~mm} \mathrm{Hg}$, or $15 / 10 \mathrm{~mm} \mathrm{Hg}$ above the minimum goal of 135/85 mm $\mathrm{Hg}$ set for Blacks with two drugs, 3 in comparison with the Seventh Report of the Joint National Committee on Prevention, Detection, Evaluation, and Treatment of High Blood Pressure (JNC 7) criteria of 160/100 $\mathrm{mm} \mathrm{Hg}$ or 20/10 $\mathrm{mm} \mathrm{Hg}$ in all patients with hypertension? How do you approach single -drug therapy or combination therapy?

B: Generally the level of BP at baseline is the primary determinant of whether two-drug therapy or single-drug therapy is initiated... [Medical Roundtable].

\subsection{Imposing a communicative initiative tactic}

Imposing a communicative initiative tactic should be distinguished from passing a communicative initiative tactic because the former is realized due to speaker's effort and contrary to listener's will. The analysis of medical professional discussions has shown that the usage of imposing a communicative initiative is not specific for communicative behavior of medical professional discussion participants. A proposal of the right to talk next is supposed to be expected for participants. Turn-taking process in medical professional 
discussion is performed by mutual partners' agreement. But there is a slight variation in extent of directive mitigation. The mentioned tactic can be realized by both a call for taking a communicative initiative (Can you tell us about the ERSPC study design and results and how you have interpreted the findings? / Dr. Gradman, do you have an opinion on guidelines?) and strict directive (David, tell me, what are we missing... I I want to hear your thoughts on that issue...). A call is considered as a soft form for redistribution of the speaker's and the listener's roles.

The listener can also impact the turn-taking process utilizing taking an initiative tactic and capturing an initiative tactic. The most frequent tactic within the analyzed is taking a communicative initiative. Using this tactic a listener, as a rule, has to state his intention to join a talk-in-interaction. Semantic meaning of such utterances can be defined as "I want to add (express my opinion concerning a discussed issue)": Bill, I want to respond to the part of your question... / I would like to also support that notion... / Dave, I would like to add to that....Using verbs in the subjunctive mood in these utterances allow mitigating a categoricalness of the first phrase, so the second and the third ones seem to be more polite and accepted in formal talk.

The analysis of medical professional discussions has shown that a capturing an initiative tactic is of rare occurrence, so this fact give us an opportunity to think that interrupting a communicative partner is not conventionally accepted in moderated discussions. Here is the only one example of capturing an initiative. Situational context: A, B - invited experts.

A: ... Dabiratran has some advantages, in terms of ease-of-use and it doesn't require as many dietary restrictions, although there are interactions with amiodarone and dronedarone....

B: I would point out that dabiratran is costly, about $5 \$$ a pill.

A: It is costly, but most insurance carriers have been willing to cover it with reasonable co-pay... [Medical Roundtable].

This dialogue shows us that the second speaker starts to talk before the previous speaker has finished. He violates accepted conventions expressing his objection not at transitional relevant point, nevertheless the first speaker return his right to talk by giving a counterargument.

\subsection{Keeping an initiative tactic}

The realization of keeping an initiative tactic is highly rare represented in analyzed material. We consider this fact is caused by that capturing an initiative is not conventionally approved, and communicative partners always wait for the end of a current speaker's utterance, so the next speaker does not have to produce special efforts for keeping a communicative initiative. However, keeping an initiative can be conducted by speaking expert efforts. The current speaker may insist on his right to talk by using metacommunicative signals. It should be appreciated that there is a specific distinction between the metacommunicative signal and the metatextual commentary. As the former is not in initial position in the utterance, it indicates a speaker's intention to keep the right to talk.

A: Matt, should elderly patients be started on two drugs?

B: Well, let me first go on record and say I object to the word "elderly"... As for the medication I would use, I think we have good supportive evidence for the use of thiazide diuretics, CCBs, and drugs that block the RAS [Medical Roundtable].

Here the second speaker, taking an initiative, digresses the topic of the discussion proposed by the moderator and expresses an objection against applying the term "elderly people", then he moves his answer to the topic, marking the return with a metacommunicative signal semantic content "As for your question...".

\subsection{Closing an interaction tactic}

Delimitation of communicative process is important for defining a closing interaction tactic. Based on assumption that communicative process is continued, it is possible to distinguish a discrete unit of communicative process, communicative event [11]. This unit is believed to be limited and can be simple or composite [12]. The latter is composed of communicative episodes, possessing their own boundaries. These boundaries are set by an intention shift and introducing of a new thematic proposal. Thus, an utterance, changing the topic and containing a new illocutionary force should be supposed to be the beginning of a communicative episode. The ending of a communicative episode can be verbally marked or does not contain specific signals, expressing completeness [13]. Understanding between the partners is achieved "by means of cues both prospectively and retrospectively through the context" [14]. Verbally marked endings of communicative episodes should be differentiated into: signals of informative completeness, signals of emotional fatigue, voluntary signals of completeness, informative retardation, situational delimitative signals, and signals of pragmatic depletion. The absence of specific signals marking the ending of a communicative episode does not affect communicative development, because participants in conversation accurately define, when a new episode in discussion development begins.

Obviously, participants should make definite taskoriented efforts for joining the conversation and for its closing. These efforts comprise the means of closing an interaction tactic realization. The one-side coming out of an interaction becomes the most difficult in realization. Communicative turns composing closing an interaction tactic are classified into direct, indirect, and accessory. Choosing the most effective communicative turns within the scope of closing an interaction tactic is determined by parameters of communicative situation (social status and role of participants, conversational mood, official format of communicative situation, etc.) 
Medical professional discussion is aimed to searching and distribution of obtained scientific knowledge and experience. Scientific communicative ethic requires mutual respect of participant in discussion and a productive conduct of scientific discussion. The material analysis has shown that the most frequent are indirect communicative turns, which assist in softly close discussing one aspect of the issue and move to another one. Communicative turns pointing directly to closing interaction are not conventionally accepted in medical professional discussions. Signals of pragmatic depletion as direct communicative turns may be utilized in at the final stage of the discussion or as means of positive assessment of a communicative partner. Accessory communicative turns are observed in changing a communicative partner or actualizing a new topic.

Discussing in the scope of one communicative episode can be limited by means of informative completeness signals.

A: Dr. G., do you have an opinion on guidelines?

B: Part of what is going on in the revised hypertension guidelines is a worldwide shift from the treatment of individual patients to the treatment of patient populations./... I think there are different audiences; a good general guideline today should be aimed at primary care physicians but I think specialists need their own guidelines. As a cardiologist, I would want a very different set of guidelines than is presented in JNC 8.

A: Dr. M., given your long association with the highly successful parent of the JNC process, the National High Blood Pressure Education Program, I think your perspective is invaluable. Do you think any of the current guidelines hit the mark or what do you think should have been done differently? [Medical Roundtable].

Here communicative episode is represented by two utterances. The first speaker's communicative intention is to find out the second speaker's position concerning existing hypertension guidelines. The second speaker expresses his point of view, emphasizing medical specialists' necessity in their own guidelines. Thematic development of the second speaker's utterance is summarized by communicative turn "As $a$ cardiologist...", that points indirectly to answer completeness and results in closing a discussion. Then the moderator moves to the next information request. Changing a communicative partner by a moderator is an accessory signal, marking the ending of communicative episode.

The material analysis allows representing the structure of a communicative event as a set of topically related communicative episodes, restricted by the single global communicative goal - to produce new scientific knowledge concerning the announced discussion topic. Each communicative episode can include a simple turn taking or adjacent pair (a question - an answer), or can include additional utterances (a question - an answer clarifying question - an explanation, etc.). Thus, as each communicative episode is aimed to expressing a viewpoint of a participant and its proving with arguments, then responding utterances are rather long.
To actualize a viewpoint in responding utterances preliminary conclusions are used, indirectly pointing to completeness in discussing the current issue. Formal markers can be represented by means of: at the end of the day, I believe that ... / I think that... / Again, I think... / So I would at least point out... / Otherwise, etc.

Voluntary signals of completeness can be used for closing discussing a subtopic in case participants digress a lot from a proposed topic. Let us give an example of a discussion about the controversy of dialysate Calcium concentration. Discussing calcium concentration, participants move to the subtopic about level of potassium and magnesium, that is why one of the experts has to apply voluntary signal of completeness in order to redirect the conversation back to the previous topic. Situational context: A, B - invited experts.

K.1: Absolutely, Allan. We, as nephrologists, are always worried about the high potassium, but our cardiology colleagues impress upon us that a low potassium is also arrhythmogenic and associated with increased mortality, so this perfect storm that you speak of, of a low calcium, a low potassium, a low magnesium in the presence of a high bicarbonate is potentially, incredibly arrhythmogenic and may well explain much of the mortality at the end of those dialysis treatments.

K.2: I completely agree that we should avoid this kind of storm during the dialysis session. There are so many changes in the different ions that could trigger some arrhythmia. I completely agree that we should avoid important gradients, whether the ion is calcium or potassium. Now we're discussing calcium... [Medical Roundtable].

Expressing an agreement with expert's position disarm a communicative partner, as necessity of further persuasion disappears. The speaker intensifies his agreement with adverb completely, and then he successfully actualizes the previous topic concerning the calcium balance in dialysate and its estimation technique. Thus, direction of discussion development is restored.

The most frequent markers of not only a communicative episode but also a communicative event as a whole are signals of pragmatic depletion. Taskoriented communication in practical or intellectual spheres is limited by successful result achievement (obtaining or detailing information, making the best possible decision for discussed issue). Leading intention defines the limits of a communicative episode and signals marking the ending of a communicative event are closely connected with the communicative situation. Medical professional discussion as a formal communicative event has strictly defined time constraints. Interaction in this sphere is regulated, that is why a moderator governs discussion development. Closing an interaction always requires verbally formalized farewell. The most frequent are utterances pointing a lack of time to continue a discussion: $D r . P$., is there time left to talk about the disadvantages of vasoconstrictors? / I think that's fantastic point, and one that's great to end with... / Dr. M., you have the last word; my last question to everybody is.... 
These signals allow participants understand the discussion is over. It is usually conventionally accepted to thank all participants for taking part in discussing and expressing their valuable viewpoints.

K.1: One last question on this topic; the role of CPX testing in trials and device approvals. ... Is there a submaximal measure that one can get from a CPX test that might be similarly indicative of functional capacity that would not require a maximal test?

K.2: Yes, one of the benefits of some of the markers of ventilatory inefficiency, such as the VE/VCO2 slope, is that it doesn't require a maximal effort to be of value. ... With the VE/VCO2 slope and most of the other markers of ventilatory inefficiency, one doesn't need a maximal test. It's another reason to advocate the use of those markers in addition to peak VO2 in a clinical trial.

K.1: That's very insightful. Thank you, Jon and Dave. I believe that we've covered the landscape here: how to do a CPX test, what are good markers, the role of CPX in clinical care, how CPX testing can give us other information on the clinical status of our patients and prognosis, as well as the role of CPX testing in clinical trials. Thank you both [Medical Roundtable].

The final utterance comprises not only positive assessment of the previous speaker but also a signal of pragmatic depletion, marking all goals achievement. The communicative event is finished by summarizing participants' views and drawing a conclusion. Circular composition of the utterance is made by repetition of saying "thank you" that helps to emphasize an important and valuable contribution of each invited experts to the discussion development.

\section{Conclusions}

The present study of medical professional discussions has shown that turn-taking is accomplished mainly due to the moderator's efforts by means of passing a communicative initiative tactic. Turn-taking by means of listener's efforts is realized by taking an initiative tactic or capturing an initiative tactic. Keeping an initiative is accomplished through a communicative turn "I have something to talk (to add)", pointing the speaker's intention to save the right to talk. Closing an interaction tactic is realized more effectively by means of indirect communicative turns, as this type of turns assists in soft closing a discussion of one subtopic and moving to another one. Direct communicative turns are represented by means of signals of pragmatic depletion, as this type of turns assists in drawing a conclusion and marking the end of interaction. Accessory communicative turns are observed in changing a communicative partner or moving to a new topic.

\section{References}

1. N.B. Egorchenkova, N.L. Shamne Science Journal of VolSU. Linguistics, 15(1), 2016.

2. B. Maroni, A. Gnisci, C. Pontecorvo European Journal of Psychology of Education, XXIII (1), 5976,2008
3. M.L. Makarov The foundation of discourse theory (Moscow, 2003)

4. N.V. Yashina A human being in informational space, 213-218, 2014

5. J. Heritage Conversational analysis and institutional talk in Qualitative research: theory, method and practice (London, 1998)

6. G. Pianese Spoken discourse: types in Encyclopedia of language and linguistics (2006)

7. E. A. Schegloff Sequence of organization in interaction: a primer in conversation analysis (Cambridge University Press, 2007)

8. O. Akay, A. Kalashnikova, I. Kalashnikov, A. Golubeva ASSEHR, 97, 9-14, 2017

9. O.S. Issers Communicative strategies and tactics of Russian speech (Moscow, 2006)

10. V.A. Litvinova Science Journal of VolSU. Linguistics, 16(2), 2017

11. I.N. Borisova Russian dialogue: structure and dynamics (Moscow, 2009)

12. O.N. Dubrovskaya Izv. Saratov Univ. (N.S.), Ser. Philology. Journalism, 1, 3-9, 2008

13. E.A. Schegloff, H. Sacks Semiotika, 8, 289-327, 1973

14. N.L. Shamne Actual problems of intercultural communication (Volgograd, 2014) 